\title{
Measuring Rice Farmer's Pesticide Overuse Practice and the Determinants: A Statistical Analysis Based on Data Collected in Jiangsu and Anhui Provinces of China
}

\author{
Jianhua Wang ${ }^{1,2}$, May Chu ${ }^{3}$ (iD) and Yuting Ma ${ }^{4,5, *}$ \\ 1 School of Business, Jiangnan University, Wuxi 214122, China; jianhua.w@jiangnan.edu.cn \\ 2 Food Safety Research Base of Jiangsu Province, Jiangnan University, Wuxi 214122, China \\ 3 Department of Government and Public Administration, The Chinese University of Hong Kong, \\ Hong Kong, China; maychu@cuhk.edu.hk \\ 4 School of Economics and Management, Wuhan University, Wuhan 430072, China \\ 5 Economic Development Research Center, Wuhan University, Wuhan 430072, China \\ * Correspondence: jade1016@whu.edu.cn
}

Received: 24 December 2017; Accepted: 27 February 2018; Published: 2 March 2018

\begin{abstract}
Understanding the extent of pesticide overuse and what drives rice farmers to overuse pesticide in agricultural production theoretically and empirically is imperative to increase farmers' income, promote agricultural transformation and agricultural sustainable development. In this paper, we examined the phenomenon and pattern of pesticides overuse based on the data collected from 861 rice farmers in Jiangsu and Anhui, two provinces in China. By applying the Cobb-Douglas production function (C-D production function) and the damage control model, we estimated the marginal productivity of pesticides. We also adopted the Binary Probit model to further explore factors leading to overuse of pesticide among farmers. Our findings suggested that the marginal productivity of pesticides is close to zero, indicating that there is an excessive use of pesticides in the surveyed areas. According to the Binary Probit model, we also discovered that female farmers, farmers with knowledge about pesticide toxicity, pesticide residue and farmers who hold the view that massive use of pesticide is inimical to the environment, and farmers who participate in pesticide training organized by the government, are more likely to overuse pesticide. On the contrary, experienced farmers have a lower chance of overusing pesticides. Possible explanations to the above findings may be that applying pesticides in accordance with the instructions causes overusing and farmers who are loss-averse, in order to avoid the risk of income loss that may be caused by disease and insect pests, and keep its own income stable, will still increase the amount of pesticide application. It also indicates that farmers are insensitive to increased pesticide overuse.
\end{abstract}

Keywords: pesticide overuse; marginal productivity; rice production; C-D production function model; damage control model

\section{Introduction}

In the agricultural sector, pesticide is commonly used to prevent, destroy, repel or mitigate pests, weeds, insect infestation, and diseases. It plays a significant role in enhancing crop productivity, ensuring food stability, and reducing farmers' income loss due to pest diseases. According to the statistics analyzed by Liu et al. [1], the loss of pests and weed losses recovered by pesticide application worldwide account for one third of the total grain output. Given the constant growth in world population and increasing demand for food safety, use of pesticide is crucial to ensure food security. 
Despite the aforementioned benefits, overuse of pesticides could pose a number of risks to human beings, animals, and the environment. The high-risk groups exposed to the adverse consequences of overusing pesticides include farm workers, sprayers, and mixers. Pesticide overuse is a common and long-term phenomenon in developing countries. China is the largest developing country and is now the largest manufacturer and consumer of pesticides in the world, while pesticide overuse is also common in the region [2]. The average amount of chemical pesticides per unit area in China is 2.5 to 5 times higher than developed countries [3]. Sustainable land management is another issue that has arisen from pesticide overuse as pesticides could contaminate soil, water, turf, and other vegetation. Some research has shown that more than 10 million $\mathrm{mu}(\mathrm{mu}$ is a measure for land area in China; $15 \mathrm{mu}=1$ hectare) of crops are contaminated by pesticide residues every year [3]. Even though pesticide is effective to kill insects and weeds, it can be toxic to a host of other organisms including birds, fish, beneficial insects, and non-target plants (https:/ / www.ncbi.nlm.nih.gov/pmc/articles/ PMC2984095/). Only 30\% of pesticides are in actual use, while the remaining 70\% is dissipated in the environment. Moreover, pesticide overuse imposes a burdensome cost on farmers during agricultural production. In other words, holding productivity unchanged, a decrease in the use of pesticides can increase farmers' income.

Studies about pesticide overuse are essential to improve our understanding of how pesticide overuse can be determined or measured, and how reducing the use of pesticides can increase farmers' income and alleviate environmental harm. This study analyzed the significance of reducing the use of pesticide to increase farmers' income and promote agricultural transformation from the perspective of economic efficiency. Thus, surveys in two provinces (Jiangsu and Anhui provinces) in China were conducted and the Cobb-Douglas (C-D) production function and the damage control model was applied to estimate the marginal productivity of pesticides. Based on the findings we obtained and by Binary Probit Regression, this paper further analyzed how the behavior of overuse can be explained.

This paper is structured as follows. Section 1 introduces the background on China's current pesticide use in agricultural production and the significance of reducing the amount of pesticide application. In Section 2, we review previous studies about marginal productivity of pesticides and the factors influencing pesticide application. Next, Section 3 presents our data sources and analytic methods. In Section 4, we offer descriptive statistics, followed by the key findings and provide a series of in-depth arguments to elaborate on the findings of our quantitative analysis. Finally, in Section 5, we draw our conclusions, discuss our research contribution and policy implications.

\section{Literature Review}

\subsection{Comprehensive Rationality and Prospect Theory}

The most direct theory has always been inseparable from the theory of comprehensive rationality to study the behavior choice of humankind. In classical economics, one of the key assumptions is that all human beings are rational and they tend to maximize their own utility when making decisions. The term 'comprehensive rationality' was coined to describe such behavior. In terms of the field of agricultural production, the US economist Schultz [4], argues that "farmers all over the world are in the calculation of costs and profits, and they are always pursuing their personal profit maximization".

Prospect theory is a behavioral economic theory that describes the way people choose between probabilistic alternatives that involve risk, where the probabilities of outcomes are known. The theory was created in 1979 by Daniel Kahneman and Amos Tversky as a psychologically more accurate description of decision making, compared to the expected utility theory. The theory states that people make decisions based on the potential value of losses and gains rather than the final outcome, and that people evaluate these losses and gains using certain heuristics [5]. 


\subsection{Measuring Marginal Productivity of Pesticides and Determining Overuse}

In the absence of pest attacks, using pesticides would only result in having extra costs without generating benefits. Nevertheless, farmers would apply high doses of, and disproportionate combinations of, several pesticides frequently in order to manage pests when necessary. This would lead to the emergence of the 'pesticide treadmill' in certain areas. Farmers in developing countries, in particular, continue to use pesticides at increasing rates [6]. A pesticide use policy is needed to address the above issue [7]. Empirical studies are also necessary to evaluate pesticide use.

During the last three decades, numerous studies have attempted to estimate the productivity of chemical pesticides in agricultural production. These studies can be divided into two groups depending upon their method used [8]. While one group uses the generic Cobb-Douglas production functions, the other uses a variant of it by taking the unique characteristics of pesticides into consideration. Almost all of the first generation studies [9-11], mostly adopting a Cobb-Douglas function to measure production elasticity of the inputs so to compute marginal products, evaluating the economic performance of pesticides within the production function framework using non-linear functional forms, concluded that the value of marginal product of pesticides exceeds that of marginal factor costs. Headley was the first one to regard pesticides as an input and used the C-D production function to calculate marginal products of pesticides, and he has shown that about USD3.90 to USD5.66 of marginal revenue was generated by per dollar pesticide expenditure, denoting that farmers can increase their profitability by increasing the amount of pesticides [9]. Campbell used input and output data from a cross-sectional sample of tree-fruit farms in British Columbia to estimate the marginal productivity of agricultural pesticides. His analysis indicated that the marginal dollar worth of pesticides input yielded around $\$ 12$ worth of output [10]. This result is similar to that obtained by Headley. Fernandez-Comejo, Jans, and Smith estimated pesticide productivity of corn using 1991 farm-level cross-sectional survey data from 18 corn-producing states [12]. They found that the marginal return of pesticides used on corn was $\$ 1.89$ per dollar of pesticide expenditure. This estimation was far below Headly and Campbell's estimations.

However, there are other studies that believe that the C-D production function might have overestimated pesticide productivity. Pesticides do not enhance productivity directly like other standard factors of production such as land, labor, and capital. Rather, they help farmers to combat pests that would otherwise reduce agricultural output. Thus, pesticide should be regarded as damage control agents [13], which differ it from other inputs in agricultural production. Lichtenberg and Zilberman [14], for example, argued that first generation studies may have failed to capture the nature of pesticide as a damage control agent. They suggested that considering the actual (realized) output (net result of potential yield and potential loss due to pests) can contribute to a better understanding of the role of damage control agent in production. Similarly, Babcock et al. analyzed pesticide use in North Carolina apple production using the damage control approach [13]. The result showed that a Cobb-Douglas specification gives a substantially larger estimation of fungicide productivity than the damage control specification. In other words, pesticide use needs to be conceptualized in terms of its role in preventing output losses.

Actually, the damage control model has been widely used in recent decades to study marginal productivity of pesticides in rice, cotton and vegetable production, which all further suggested that pesticides are over-utilized [15-17]. For example, Huang et al., in their analysis of rice farming in China, suggested that, on the one hand, pesticides contribute significantly to increase rice production; on the other hand, the marginal contribution of pesticides decline considerably with increasing use of pesticides and approached zero at current average pesticide use level by the rice farmers [15]. Hence, this study proposes to use both approaches to determine the marginal productivity of pesticides, and further better define pesticide overuse and unearth the factors contributing to pesticide overuse. 


\subsection{Factors Attributing to Pesticide Application}

There are a number of studies examining factors affecting compliance behavior of pesticide use among farmers. Gong et al. used the data collected from 800 farming households in Hubei and Hainan Province to study how characteristics and values upheld by farmers, influence their pesticides usage behaviors. The result indicated that farmers' gender, education background, size of farming, family size and their attitude towards environmental conservation have significant effects on their pesticide use behaviors [18]. Both Abhilash and Singh's and Stadlinger et al.'s studies found that the lack of professional knowledge and understanding on pesticide use is the key factor attributing to pesticide overuse and misuse $[19,20]$. A similar finding was presented by Zhao et al., showing that those who: have low education level, fail to acquire pesticide use knowledge and lack understanding on the adverse impact of pesticides, are more likely to apply pesticides with high toxicity [21]. Jia et al. collected survey data from vegetable growers in Hebei Province and concluded that experienced farmers tend to rely on their past experience in pesticide application and are more likely to overuse pesticide [22]. Hashemi et al. delved deep into this subject and found that experienced farmers are more alert to the negative impacts of pesticides and hence are more likely to adopt protective measures when applying pesticides [23]. Apart from the above perspectives, participation in pesticide use training is another factor influencing pesticide use behaviors among farmers. For instance, various studies conducted by Wu et al. and Wang et al. found that farmers who participated in pesticide use trainings are more likely to use pesticide properly, and are more aware of the amount of pesticide doses and "pre-harvest interval" [24,25]. However, Zhang et al. and Zhou et al. have an inconsistent result, arguing that farmers who received training tend to misuse pesticides [26,27].

However, previous studies have discussed factors contributing to pesticide application, including the type, the amount and the number of pesticide application as well as pesticide ratio [28-30]. Further, a few other studies have investigated the determinants of pesticide compliance, but this measure does not necessarily mean that farmers are using pesticides at their optimal levels. Note that those measures relate to the volume of pesticide application and are not necessarily indicate pesticide overuse. For example, based on experimental results of the degree of risk aversion, Mi et al. [2] conducted an empirical analysis of the relationship between risk aversion and the amount of pesticide application and found that farmers with higher degree of risk aversion have overused pesticides to avoid possible damages from insects. However, they have defined pesticide overuse as the number of pesticide applications and thus failed to show how much pesticide is optimal. In fact, a clear definition of pesticide overuse is rare. To filled this gap, we set up our models to define and measure 'overuse' in view of the economic rationalization by estimating the marginal productivity of pesticide (see the C-D production function model and the damage control model introduced below).

\section{Materials and Methods}

\subsection{Case Selection}

Rice production was selected as our case study since China is the largest producer and consumer of rice in the world, with an annual production and consumption of 2 billion tons respectively [31]. Compared with corn and wheat, rice production consumes the most pesticides. In the meanwhile, it was shown that the application of pesticides in the rice production accounts for approximately $15 \%$ of the total pesticide consumption in China [32]. Along with the rising living standard in China, Chinese consumers' demand for rice has shifted from quantity to quality. Based on the above reasons, rice production would be an illustrative case for our study.

\subsection{Data Collection}

A pilot study was conducted in May 2016 at Huaian, a prefecture-level city in Jiangsu Province, to identify potential practical difficulties we may encounter in the subsequent research. Huaian city 
was selected as the site for the pilot study because it is a traditional agricultural area and it serves as a major grain producer in China. The final questionnaire was then revised based on the pilot study.

Our actual survey was then implemented from June to September 2016 in Jiangsu Province and Anhui Province. Jiangsu Province and Anhui Province belong to the East region of China, and belong to the important grain-producing provinces of China. The main food crops in Jiangsu and Anhui are same, such as rice and wheat. Thus, we can better analyze pesticide application of rice farmers in these two Provinces. To ensure data reliability, we adopted a combination of hierarchical design and random sampling to select our area of fieldwork. Accordingly, eight prefecture-level cities were selected in Jiangsu Province, including Suzhou, Wuxi, Changzhou, Taizhou, Nantong, Yangzhou, Huaian, and Lianyungang. Similarly, four prefecture-level cities were selected in Anhui Province, including Bengbu, Luan, Chaohu, and Tongling. Moreover, three villages were then selected from every prefecture-level city above by random sampling based on their production scale and income level.

Our questionnaire was given out to farmers who have applied pesticides during rice production. Interviews were conducted face-to-face with farmers by enumerators (i.e., university students) who speak the local dialects to ensure that the biases from the language were minimized. Note that our survey area is located at the Jianghuai Plain where multiple crops were grown, i.e., rice is grown rotate with rice. Because of the fact that only two crops were grown and that the two crops were grown at different times, during our survey farmers were found to have provided relatively accurate input and output data for rice production. A total of 900 questionnaires (765 in Jiangsu Province, 135 in Anhui Province) were distributed, among which 861 were valid (response rate 95.7\%). The invalid questionnaires were because of the respondents' insufficient knowledge to understand the questions although being carefully interpreted by enumerators. In the following analysis, the questions we selected did not have missing data.

\subsection{Estimated Marginal Productivity of Pesticides}

\subsubsection{Model Framework for Marginal Productivity of Pesticides}

To accurately examine whether farmers overuse pesticides, it is necessary to clarify how marginal productivity of pesticides is measured. Based on the assumption of profit maximization [33], the net income function of farmers can be built as:

$$
\max _{Z} p F(X, Z)-\sum_{i} r_{i} X_{i}-w Z
$$

where $p$ is the price of the agricultural product, $Z$ is the amount of pesticide use, $X_{i}$ is the amount of other standard yield-enhancing inputs except pesticides, $F($.$) is the production function, \mathrm{w}$ is the price of pesticide, and $r_{i}$ is the price of other standard yield-enhancing inputs. When both pesticide and grain markets are perfectly competitive, the optimal use of pesticide is:

$$
p F_{z}(X, Z)=w
$$

where $F_{z}(X, Z)$ is the derivative of the function of the variable $Z$, and $p F_{z}(X, Z)$ is the value of marginal product (VMP) of pesticides.

Optimal pesticide use amount is determined by VMP equals the price of pesticides $(w)$. The marginal productivity of pesticides is calculated by the income generated by per additional unit of pesticide divided by per unit price of pesticide (i.e., $\mathrm{VMP} / w$ ), which means the marginal value product per unit cost of pesticides. When $\mathrm{VMP} / w$ is larger than 1 , it indicates that pesticides are under-utilized and farmers can increase their profitability by increasing the amount of pesticides used. On the other hand, when $\mathrm{VMP} / w$ is smaller than 1 , it denotes that pesticides are over-utilized and farmers can increase their profitability by decreasing the amount of pesticides used. Optimal use of pesticides is denoted by VMP/w equals 1 [34]. When the price of pesticides is fixed, the estimation of VMP is crucial to the calculation of marginal productivity of pesticides. 
Based on microeconomics theories, VMP can be characterized as first increasing and then decreasing monotonically, and finally converging to zero (as shown by the dotted line in Figure 1, the C-D production function is widely used to estimate VMP. C-D production can be represented by the following formula:

$$
Y=F(X, Z)=\lambda Z^{\beta} \prod_{i=1}^{n} X_{i}^{\alpha_{i}}
$$

where $Y$ is production quantity, $Z$ is the amount of pesticide use, and $X_{i}$ is the amount of other standard yield-enhancing inputs such as machine input, labor input, and fertilizer input. $\alpha$ and $\beta$ are the parameters that needed to be estimated. VMP calculated by the C-D production function is shown by line A in Figure 1.

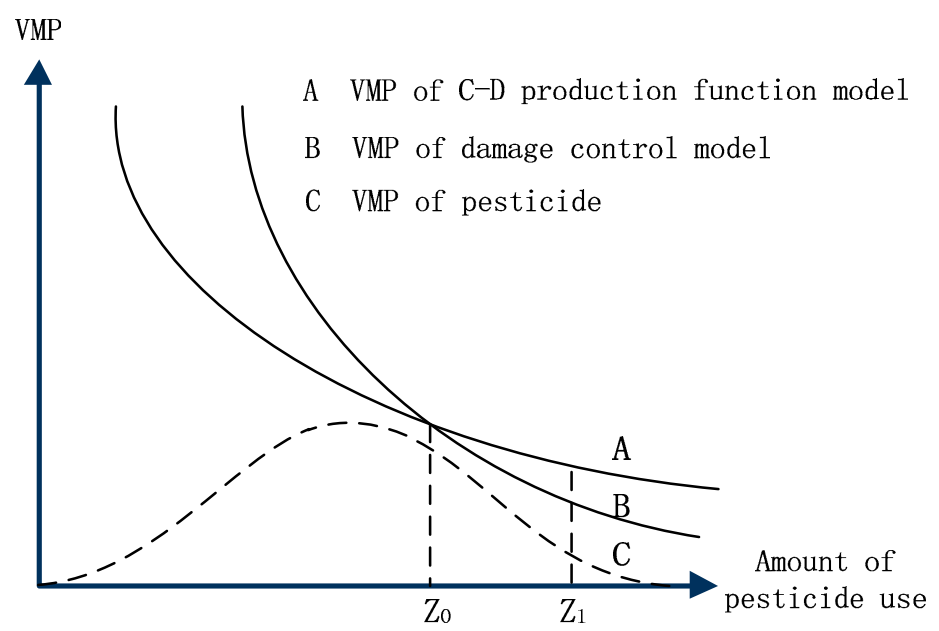

Figure 1. Estimated marginal productivity of pesticides based on the Cobb-Douglas (C-D) production function model and the damage control model.

Lichtenberg and Zilberman [14] adopted damage control functions to estimate VMP of pesticides, represented by the formula:

$$
Y=F[X, G(Z)]
$$

For simplicity, Equation (4) [35] could be simplified as:

$$
Y=F(X) G(Z)
$$

where $Y$ is production quantity, $Z$ is the amount of pesticide use, and $G(\cdot)$ can be described by the distribution function of the damage control model. $X_{i}$ as the amount of other standard yield-enhancing inputs such as machine input, labor input, and fertilizer input; and $F(\cdot)$ can be described by the C-D production function, notably concavity in $(X, G)$. The actual output was characterized as a combination of potential output and losses of production. When the destructive capacity of damaging agents is completely eliminated, losses will be zero and actual output will equal potential output, that is, potential output can be expressed as $F(X, 1)$. When $G=0, F(X, 0)$ denotes the output under maximum destructive capacity, i.e., the minimum actual output. Optimal use of pesticide could be denoted by $p F_{X}(X) g(Z)=w$, where $g$ is the probability density function of the distribution function of the damage control model, as demonstrated by line B in Figure 1.

In Figure 1, the functions of C-D production function and the damage control model intercept at point $Z_{0}$. When the amount of pesticide use is less than $Z_{0}$, the C-D production function is closer to the VMP line, implying that the C-D production function model serves better in estimating VMP. On the contrary, when the amount of pesticide use exceeds $Z_{0}$, the damage control model is closer to the VMP line, implying that the damage control model serves as a better estimation of VMP. Note that line $C$ 
refers to the theoretically "real" VMP of pesticide use whereas lines A and B can be modelled by the C-D production function and damage control model, respectively.

\subsubsection{Regression Model of Marginal Productivity of Pesticide}

Based on Equations (3) and (5) above, there are two approaches to build our regression model. First, we independently analyze the relationship between inputs and outputs, regardless of the factor of price $[16,17]$. Second, we include the factor of price and analyze the relationship between cost and revenue $[9,36]$. Due to the diverged variety of pesticides, it is impractical and impossible to calculate the exact amount of pesticide use. As a remedy, some previous research has chosen one single type of pesticide for the estimation of marginal productivity of pesticides [37]. However, this approach fails to capture the total quantity of pesticide use. In light of this deficiency, we have selected the second approach, which studies the relationship between the cost of different inputs and the total revenue of rice production. To evaluate the relative accuracy of the C-D production function model and the damage control model, two equations are set up as follows:

$$
\begin{aligned}
& \ln \left(Y_{n}\right)=a+\sum \beta_{i} \ln \left(X_{i n}\right)+\beta_{0} \ln \left(Z_{n}\right)+v_{n} \\
& \ln \left(Y_{n}\right)=a+\sum \beta_{i} \ln \left(X_{i n}\right)+\ln \left(G\left(Z_{n}\right)\right)+v_{n}
\end{aligned}
$$

where $Y_{n}$ is the rice production revenue of the Nth farmer, $\alpha$ and $\beta$ is the parameters needed to be estimated, $v$ is the random error, $X$ is the cost of other standard yield-enhancing inputs except pesticides, $Z$ is the cost of pesticides use, and $G(Z)$ is the distribution function of the damage control model. In addition to seed, fertilizer, machine and labor inputs, we also add transportation input in our analysis [38].

Four separate damage control functions for pesticide use in agriculture are identified by Talpaz and Borosh [39]:

$$
\begin{gathered}
\text { Pareto: } G(Z)=1-K^{\lambda} Z^{-\lambda} \\
\text { Exponential : } G(Z)=1-\exp (-\alpha Z) \\
\text { Logistic: } G(Z)=(1-\exp (\mu-\sigma Z))^{-1} \\
\text { Weibull : } G(Z)=1-\exp \left(-Z^{\gamma}\right)
\end{gathered}
$$

where $K, \lambda, \alpha, \mu, \sigma$ and $\gamma$ are damage control parameters that need to be estimated. Since the density function of Pareto distribution implies that the output is inelastic, which fails to describe the key features of the damage control model [14], we decided not to consider this type of distribution.

\subsection{Regression Model of Drivers to Pesticide Overuse}

Based on the above analysis, it can be concluded that pesticide overuse is a common and ongoing trend. This argument coincides with previous studies which focus on other countries $[8,17]$. In this section, we aim to study the factors contributing to overuse and explain such phenomenon based on farmers' individual background, characteristics and knowledge.

We applied Binary Probit Regression [40] to analyze factors causing pesticide overuse, the model is shown as follow:

$$
P_{r}\left(Y_{i}>0 \mid X_{i}\right)=\ln \frac{p(Y=1)}{1-P(Y=1)}=\alpha+\sum_{i=1}^{n} \beta_{i} X_{i}+\varepsilon
$$

where $Y$ is the dummy variable on pesticide overuse ( $Y=1$ for overuse; $Y=0$ for otherwise), $X_{i}$ is various independent variables explaining pesticide overuse. (Overuse means the marginal productivity of pesticides is less than 1 and we estimate the marginal productivity of pesticides of 861 farmers by the C-D production function and the damage control model to redefine $Y$, when the marginal productivity of pesticides is less than $1, Y=1$; otherwise, $Y=0$ ). It should be pointed out that the measurement of 
pesticide overuse here is still using the above calculation method to calculate the pesticide marginal productivity of each sample of farmers, and then defined $Y$ as 1 or 0.

\section{Results and Discussion}

\subsection{Descriptive Statistics of the Survey}

Table 1 shows the general profile of our respondents. Our respondents generally: (1) belong to the older age groups; (2) have rather a low level of education; (3) have part-time job other than farming; (4) have work experience other than farming; (5) have a family size of 5 members or above; (6) have an annual household income of RMB 30,000-50,000; (7) have their income from farm production accounts for $30 \%$ of their total annual income; (8) have a small size of farmland (9) are individual farmers.

Table 1. Descriptive statistic of respondents' characteristics.

\begin{tabular}{|c|c|c|c|}
\hline & Categories & $\mathbf{N}$ & $\%$ \\
\hline \multirow{2}{*}{ Gender } & Male & 441 & 51.22 \\
\hline & Female & 420 & 48.78 \\
\hline \multirow{5}{*}{ Age } & Below 18 & 3 & 0.35 \\
\hline & $18-25$ & 33 & 3.83 \\
\hline & $26-45$ & 210 & 24.39 \\
\hline & $46-60$ & 408 & 47.39 \\
\hline & 60 or above & 204 & 24.04 \\
\hline \multirow{5}{*}{ Education level } & Primary school or below & 282 & 32.75 \\
\hline & Secondary school (junior) & 315 & 36.59 \\
\hline & Secondary school (senior) & 189 & 21.95 \\
\hline & College & 54 & 6.27 \\
\hline & Bachelor degree or above & 21 & 2.44 \\
\hline \multirow{2}{*}{ Part-time jobs } & Without other part-time jobs & 234 & 27.18 \\
\hline & With other part-time jobs & 627 & 72.82 \\
\hline \multirow{4}{*}{ Household size } & $1-2$ & 51 & 5.92 \\
\hline & 3 & 201 & 23.35 \\
\hline & 4 & 243 & 28.22 \\
\hline & 5 or above & 366 & 42.51 \\
\hline \multirow{4}{*}{ Household annual income } & RMB 30,000 or below & 192 & 22.30 \\
\hline & RMB 30,000-50,000 & 261 & 30.31 \\
\hline & RMB 50,000-100,000 & 216 & 25.09 \\
\hline & RMB 10,000 or above & 192 & 22.30 \\
\hline \multirow{5}{*}{ Production mode } & Individual family farms & 819 & 95.12 \\
\hline & Large and specialized family businesses & 15 & 1.74 \\
\hline & Family farms & 9 & 1.05 \\
\hline & Farmer cooperatives & 12 & 1.39 \\
\hline & Others & 6 & 0.70 \\
\hline
\end{tabular}

Note: $6.25 \mathrm{RMB} \approx 1$ dollar (2013 data).

Table 2 summarizes our respondents' knowledge on pesticide application. Similar to other developing countries, most respondents in our study lack understanding on pesticide use in which excessive use and misuse of pesticides are commonly found. 
Table 2. Descriptive statistic of respondents' understanding of pesticide application.

\begin{tabular}{|c|c|c|c|}
\hline & Categories & $\mathbf{N}$ & $\%$ \\
\hline \multirow{2}{*}{$\begin{array}{l}\text { The use of protective measures when } \\
\text { handling pesticides }\end{array}$} & No & 372 & 43.21 \\
\hline & Yes & 489 & 56.79 \\
\hline \multirow{2}{*}{$\begin{array}{l}\text { Knowledge about "Guideline for safety } \\
\text { application of pesticides" }\end{array}$} & No & 726 & 84.32 \\
\hline & Yes & 135 & 15.68 \\
\hline \multirow{5}{*}{$\begin{array}{l}\text { To read the instructions on the label prior } \\
\text { to the application }\end{array}$} & Absolutely not & 12 & 1.39 \\
\hline & Usually not & 132 & 15.33 \\
\hline & Commonly & 303 & 35.19 \\
\hline & Usually & 279 & 32.40 \\
\hline & Surely & 135 & 15.68 \\
\hline \multirow{4}{*}{$\begin{array}{l}\text { Following the instructions and recommended } \\
\text { dose on the label }\end{array}$} & Less than the recommended dose & 27 & 3.14 \\
\hline & Following the recommended dose & 333 & 38.68 \\
\hline & More than the recommended dose & 234 & 27.18 \\
\hline & Based on previous experience & 267 & 31.01 \\
\hline \multirow{3}{*}{ Understandings of the toxicity of pesticides } & Without any understanding & 54 & 6.27 \\
\hline & With little understanding & 675 & 78.40 \\
\hline & With comprehensive understanding & 132 & 15.33 \\
\hline \multirow{2}{*}{ Knowledge about types of prohibited pesticides } & No & 459 & 53.31 \\
\hline & Yes & 402 & 46.69 \\
\hline \multirow{2}{*}{ Understanding of pesticide residue } & No & 464 & 53.89 \\
\hline & Yes & 397 & 46.11 \\
\hline \multirow{2}{*}{ Understanding of "pre-harvest interval" (PHI) } & No & 344 & 39.95 \\
\hline & Yes & 517 & 60.05 \\
\hline \multirow{2}{*}{$\begin{array}{l}\text { Judgement on whether massive use of pesticides } \\
\text { imposes harms to the surrounding environment }\end{array}$} & No & 138 & 16.03 \\
\hline & Yes & 723 & 83.97 \\
\hline
\end{tabular}

\subsection{Analysis of Marginal Productivity of Pesticides}

\subsubsection{Results}

To estimate the marginal productivity of pesticides, we have employed the following variables.

$Y$, the dependent variable, is the rice production revenue and it represents income per mu of rice (RMB). The mean value of this variable is 1430.50, while the standard deviation is 201.74.

Independent variables mainly include seed input (seed, mean $=64.22$; standard deviation $=29.38$ ), fertilizer input (fertilizer, mean $=161.31$; standard deviation $=49.97$ ), pesticide input (pesticide, mean $=98.00$; standard deviation $=42.46)$, machine input $($ machine, mean $=133.40$; standard deviation $=41.37$ ), transportation input (transportation, mean $=19.16$; standard deviation $=20.03$ ) and labor input (labor, mean $=146.50$; standard deviation $=74.33$ ). All of the above are continuous variables.

In addition, the percentages of every input in rice production is listed out in ascending order as follows: transportation cost $(3.08 \%)$, seed input $(10.31 \%)$, pesticide input $(15.74 \%)$, machine input (21.43\%), labor input $(23.53 \%)$, fertilizer input $(25.91 \%)$.

We applied the maximum likelihood estimation method to estimate the damage control model based on its non-linear feature. On the other hand, we used the ordinary least squares method to estimate the C-D production function. Both exponential and logistic distributions are not iterative converging, we will only report the results of Weibull distribution (see Table 3). 
Table 3. Results of C-D production function and damage control model.

\begin{tabular}{ccc}
\hline & \multicolumn{2}{c}{ Estimated Coefficient } \\
\cline { 2 - 3 } & C-D Production Function & $\begin{array}{c}\text { Damage Control Model } \\
\text { (Based on Weibull Distribution) }\end{array}$ \\
\hline $\mathrm{d}$ & $6.2391^{* * *}(0.1262)$ & $6.6812^{* * *}(0.1314)$ \\
Seed & $-0.0188^{*}(0.0104)$ & $-0.0189^{*}(0.0104)$ \\
Fertilizer & $0.0482^{* * *}(0.0152)$ & $0.0487^{* * *}(0.0152)$ \\
Machine & $0.0892^{* * *}(0.0153)$ & $0.0893^{* * *}(0.0153)$ \\
Labor & $0.0193^{*}(0.0117)$ & $0.0196^{*}(0.0117)$ \\
Transportation & $-0.0368^{* * *}(0.0076)$ & $-0.0369^{* * *}(0.0076)$ \\
Pesticide & $0.0354^{* * *}(0.0114)$ & - \\
$\gamma$ & - & $0.0733^{* *}(0.0337)$ \\
$R^{2}$ & 0.2050 & 0.2048 \\
$F$ Test & $16.7044^{* * *}$ & $16.6566^{* * *}$ \\
$-2 \ln L$ & 1024.8126 & 1024.5536 \\
\hline
\end{tabular}

Note: Values in parentheses are standard errors. ${ }^{*} p<0.1{ }^{* *} p<0.05 ;{ }^{* * *} p<0.01$.

\subsubsection{Discussion}

Table 3 shows similar results for both the C-D production function and the damage control model in terms of significance and their estimated parameters. The independent variables, machine input and fertilizer input, have a positive correlation with rice production revenue, and they are statistically significant at a one percent level. In contrast, transportation input has a negative correlation with rice production revenue, and they are statistically significant at a one percent level. In addition, labor input is positively correlated with rice production revenue, while seed input is negatively correlated with rice production revenue, and they are both statistically significant at a $10 \%$ level.

Based on the estimated results in Table 3, we calculated the partial derivative of $Z$ of the left and right sides of the Equations (6) and (7) and the marginal productivity of pesticides were determined. The result shows that the marginal productivity of pesticides calculated by the C-D production function and the damage control model is close to 0.39 and 0.40 respectively. In other words, each additional RMB 1 of pesticide input increases rice production revenue by RMB 0.39 and RMB 0.40 respectively. Thereby, we can conclude that farmers in our studied areas have excessively used pesticide. The close estimation of both models in our study does not support the argument that the C-D production function overestimates the marginal productivity of pesticides when compared to the damage control model. One of the possible explanations is that the current pesticide use amount does not exceed $Z_{0}$ in Figure 1; as depicted in Figure 1, when pesticide use amount is less than $Z_{0}$, the C-D production function (line A) is closer to VMP (dotted line). However, because we lack sufficient evidence to prove this explanation, we will still use both the C-D production function and damage control model for regression analysis in the following sections.

One noteworthy point is that when calculating the marginal productivity of pesticides, we have not considered the costs of human health risks and environmental risks imposed by pesticide residue. When these costs are taken into consideration, the marginal productivity of pesticide could be lower. Nonetheless, there are limitations in our study.

\subsection{Estimation of Factors Inducing Pesticide Overuse}

\subsubsection{Results}

The theory of decision making suggests that individual behavior is affected by individual characteristics, e.g., social-demographics, governmental and psychological factors [41]; based on this, our study develops 10 independent variables for analysis (see Table 4). These include characteristics of individual farmers such as their gender [42], education level [19], farming years [43], planting 
size [44], other economic features such as portion of household income generating from farming [45], government and policy factors such as the participation in pesticide use training organized by governments [46]; knowledge about types of prohibited pesticides [47], views towards frequent and massive use of pesticides on generating pesticide residue [29], view towards massive use of pesticides which in turn damage the surrounding environment [48]. In addition, we have included a new variable, which is farmer's knowledge on the "Guideline for safety application of pesticides".

Table 4. Binary Probit Regression variables definition.

\begin{tabular}{|c|c|c|c|c|}
\hline \multicolumn{2}{|c|}{ Variables } & Variable Definition & Mean & S.D. \\
\hline \multirow{2}{*}{$\begin{array}{l}\text { Overuse of } \\
\text { pesticide }(Y)\end{array}$} & $\begin{array}{l}\text { Y1 derived by C-D } \\
\text { Production Model }\end{array}$ & $\begin{array}{c}\text { Dummy variable; without } \\
\text { overuse }=0, \text { overuse }=1\end{array}$ & 0.965 & 0.183 \\
\hline & $\begin{array}{l}\text { Y2 derived by Damage } \\
\text { Control Model }\end{array}$ & $\begin{array}{l}\text { Dummy variable; without } \\
\text { overuse }=0, \text { overuse }=1\end{array}$ & 0.959 & 0.198 \\
\hline \multicolumn{2}{|r|}{ Gender } & Dummy variable; male $=0$, female $=1$ & 0.488 & 0.500 \\
\hline \multicolumn{2}{|c|}{ Education level (Education) } & $\begin{array}{c}\text { Continuous variables; Primary level } \\
\text { or below }=6, \text { Secondary school } \\
\text { (junior) }=9, \text { Secondary (senior) }=12, \\
\text { College }=14, \text { University or above }=16\end{array}$ & 9.160 & 2.769 \\
\hline \multicolumn{2}{|c|}{ Farming years (Farming) } & $\begin{array}{c}\text { Dummy variable; } 20 \text { years or less }=0, \\
\text { over } 20 \text { years }=1\end{array}$ & 0.648 & 0.478 \\
\hline \multicolumn{2}{|c|}{ Planting size (Size) } & $\begin{array}{c}\text { Continuous variables; } 3 \mathrm{mu} \text { or } \\
\text { below }=1,3-6 \mathrm{mu}=2,6-10 \mathrm{mu}=3, \\
10 \mathrm{mu} \text { or above }=4\end{array}$ & 1.864 & 0.959 \\
\hline \multicolumn{2}{|c|}{$\begin{array}{l}\text { Portion of farm income in household } \\
\text { annual income (Income) }\end{array}$} & $\begin{array}{c}\text { Interval variable; } 30 \% \text { or below }=1, \\
31-50 \%=2,51-80 \%=3,80 \% \text { or } \\
\text { above }=4\end{array}$ & 1.443 & 0.897 \\
\hline \multicolumn{2}{|c|}{$\begin{array}{l}\text { Knowledge about “Guideline for safety } \\
\text { application of pesticides" (Standard) }\end{array}$} & Dummy variable; no $=0$, yes $=1$ & 0.157 & 0.364 \\
\hline \multicolumn{2}{|c|}{$\begin{array}{l}\text { Knowledge about types of prohibited } \\
\text { pesticides (Poison) }\end{array}$} & Dummy variable; no $=0$, yes $=1$ & 0.467 & 0.499 \\
\hline \multicolumn{2}{|c|}{$\begin{array}{l}\text { Views towards frequent and massive use } \\
\text { of pesticide on generating pesticide } \\
\text { residue (Residue) }\end{array}$} & Dummy variable; no $=0$, yes $=1$ & 0.923 & 0.266 \\
\hline \multicolumn{2}{|c|}{$\begin{array}{l}\text { View towards massive use of pesticides } \\
\text { against the surrounding environment } \\
\text { (Environment) }\end{array}$} & Dummy variable; no $=0$, yes $=1$ & 0.840 & 0.367 \\
\hline \multicolumn{2}{|c|}{$\begin{array}{l}\text { Participation in pesticide training } \\
\text { organized by the government (Train) }\end{array}$} & Dummy variable; no $=0$, yes $=1$ & 0.230 & 0.421 \\
\hline
\end{tabular}

Note: $15 \mathrm{mu}=1$ hectare.

Table 5 shows an overview of Pearson correlation coefficients among the dependent variable and its influencing factors. Correlations among the explanatory variables are within the range of acceptability. Overuse of pesticide correlated significantly with Gender $(r=0.07)$, Farming $(r=-0.07)$, Poison $(r=0.08)$, Residue $(r=0.09)$, Environment $(r=0.12)$, Train $(r=0.06)$. These correlations provide preliminary results to further analysis. 
Table 5. Pearson correlation coefficients between the variables $(n=861)$.

\begin{tabular}{|c|c|c|c|c|c|c|c|c|c|c|c|}
\hline & 1 & 2 & 3 & 4 & 5 & 6 & 7 & 8 & 9 & 10 & 11 \\
\hline 1 Overuse of pesticide & 1.00 & & & & & & & & & & \\
\hline 2 Gender & $0.07^{* *}$ & 1.00 & & & & & & & & & \\
\hline 3 Education & 0.05 & $-0.10^{* * *}$ & 1.00 & & & & & & & & \\
\hline 4 Farming & $-0.07^{* *}$ & -0.04 & $-0.42^{* * *}$ & 1.00 & & & & & & & \\
\hline 5 Size & 0.03 & $-0.09 * * *$ & $0.16^{* * *}$ & $-0.10^{* * *}$ & 1.00 & & & & & & \\
\hline 6 Income & 0.01 & $-0.09 * *$ & $-0.26^{* * *}$ & $0.19^{* * *}$ & $0.08^{* *}$ & 1.00 & & & & & \\
\hline 7 Standard & -0.02 & -0.04 & $0.17^{* * *}$ & $-0.12^{* * *}$ & $0.28^{* * *}$ & -0.02 & 1.00 & & & & \\
\hline 8 Poison & $0.08^{* *}$ & -0.04 & -0.03 & $0.10^{* * *}$ & 0.03 & $0.19 * * *$ & $0.15^{* * *}$ & 1.00 & & & \\
\hline 9 Residue & $0.09 * * *$ & 0.02 & 0.05 & 0.01 & 0.05 & $-0.06 *$ & $0.09 * * *$ & $0.09^{* *}$ & 1.00 & & \\
\hline 10 Environment & $0.12^{* * *}$ & 0.01 & $0.06^{*}$ & -0.03 & $0.12^{* * *}$ & 0.01 & 0.03 & $0.07^{*}$ & 0.05 & 1.00 & \\
\hline 11 Train & 0.06 * & -0.02 & $0.20^{* * *}$ & $0.06^{*}$ & $0.22 * * *$ & -0.05 & $0.24^{* * *}$ & 0.04 & $0.10^{* * *}$ & 0.01 & 1.00 \\
\hline
\end{tabular}

Note: ${ }^{*} p<0.1 ;{ }^{* *} p<0.05 ;{ }^{* * *} p<0.01$. 
We have derived the estimated coefficients of the above independent variables by Binary Probit Regression. The result is as shown in Table 6.

Table 6. Estimation of factors inducing pesticide overuse.

\begin{tabular}{ccc}
\hline & \multicolumn{2}{c}{ Estimated Coefficients } \\
\cline { 2 - 3 } Variables & $\begin{array}{c}\text { Y Determined by } \\
\text { C-D Production Function }\end{array}$ & $\begin{array}{c}\text { Y Determined by Damage Control } \\
\text { Model (Weibull Distribution) }\end{array}$ \\
\hline Constant & $0.103(0.862)$ & $0.355(0.804)$ \\
Gender & $0.380^{* *}(0.192)$ & $0.321^{*}(0.181)$ \\
Education & $0.023(0.042)$ & $0.017(0.039)$ \\
Farming & $-0.301^{*}(0.171)$ & $-0.331^{* *}(0.166)$ \\
Size & $0.024(0.116)$ & $-0.064(0.103)$ \\
Income & $0.115(0.116)$ & $0.014(0.099)$ \\
Standard & $-0.465^{*}(0.255)$ & $-0.378(0.251)$ \\
Poison & $0.518^{* *}(0.213)$ & $0.477^{* *}(0.200)$ \\
Residue & $0.492^{*}(0.257)$ & $0.802^{* * * *}(0.223)$ \\
Environment & $0.628^{* * *}(0.195)$ & $0.535^{* * *}(0.191)$ \\
Train & $0.529^{*}(0.276)$ & $0.553^{* *}(0.267)$ \\
Restr. log likelihood & -130.178 & -146.375 \\
Akaike info criterion & 0.286 & 0.316 \\
LR statistic & $36.371^{* * *}$ & $42.865^{* * *}$ \\
\hline
\end{tabular}

Note: Values in parentheses are standard errors. ${ }^{*} p<0.1 ;{ }^{* *} p<0.05 ; * * * p<0.01$.

Table 6 shows that the estimated coefficients of the C-D production function are coherent with the damage control model in terms of the direction of correlation. Variables of Gender, Farming, Poison, Residue, Environment and Train are significant in both the C-D production function and damage control model, in which they are significant at different levels. The variable Farming has a negative correlation with pesticide overuse, the variable Gender, Farming, Poison, Residue Environment and Train are positively related to pesticide overuse.

\subsubsection{Discussion}

Firstly, in both the C-D production function and damage control model, variables of Poison, Residue and Environment have a positive correlation with pesticide overuse. In other words, farmers with knowledge about types of prohibited pesticides and farmers who uphold views towards frequent and massive use of pesticide on generating pesticide residue and massive use of pesticides against the surrounding environment are more likely to overuse pesticides. This finding casts doubts on Stadlinger et al.'s argument, which proposed that farmers' lack of environmental knowledge and concern is the key factors leading to pesticide overuse [20]. To explain this contradiction, one of the possible reasons is that farmers with the above characteristics are more likely to comply with pesticides application instructions and recommended doses, nevertheless, following the instructions and recommended doses may lead to pesticide overuse. To confirm this possibility, we particularly examined the marginal productivity of pesticides of our 333 respondents who expressed that they followed the instructions of pesticide use (Table 2). The result shows that the marginal productivity of pesticide is less than 1 , which confirms our prediction. In addition, the other important possible reason is that insecticide resistance and possible natural factors caused by long-term application of pesticides mean that farmers may even know the excessive application of pesticides may cause harm to crops and the surrounding environment, yet farmers as rational people who pursuit profit maximization will weigh the loss of their own interests caused by diseases and insect pests, and reduce the amount of pesticide application, that is, reduce the cost of pesticide inputs. As Kahneman and Tversky put forward the prospect theory, when people face future risks, they will evaluate their value through a value function. The three features of the value function include reference dependence, loss aversion and diminishing sensitivity [5]. Farmers with loss aversion characteristics feel that reducing 
the amount of pesticide application may lead to a loss that is greater than the value of increased net income, so farmers will choose to increase pesticide dosage. Therefore, for the farmers who hate loss, the purpose of excessive use of pesticides is to avoid risk and keep the stability of their own income.

Secondly, years of farming experience has a significant negative correlation with pesticide overuse. In other words, experienced farmers are less likely to overuse pesticides. This finding is similar to Damalas and Khan's study [49]. Two possible reasons can be explained. One is that, confronted with risk uncertainty, experienced farmers tend to apply pesticides according to their own practices and experiences instead of following the recommended doses to avoid risks and achieve maximum profits. The other is that farmers with rich experience have the ability to control the amount of pesticide application, that is, to control pests and diseases without excessive pesticide application, and to reduce the possibility of yield loss and income loss due to pests and diseases.

Thirdly, gender is positively correlated with pesticide overuse. Relatively, females are more likely to overuse pesticides than males. This is inconsistent with the findings of Zhou, who argued that females are more risk-averse and hence tend to apply fewer pesticides to ensure quality and safety of crops [27]. In contrast, we suggest that male farmers dominate in the process of agricultural production and they are more experienced in farming. Seen in this light, male farmers tend to apply pesticides based on their past experiences, while females tend to follow the recommended doses. This also echoes with our argument that following the instructions and recommended doses may bring about pesticide overuse.

Finally, the variable training is positively correlated to pesticide overuse. The possible reason is that farmers are only formalized to take part in training, and the related training has not achieved the desired effects. What is more, farmers who attend pesticide training organized by the government tend to apply pesticides according to the recommended dose. This also echoes with our above argument.

\section{Conclusions and Policy Implications}

In conclusion, this study examines the pesticide overuse phenomenon and pattern based on empirical data collecting from 861 rice production farmers in two provinces in China. Our findings are threefold: First, different from previous studies, we defined overuse by the marginal productivity of pesticides, rather than compliance with government regulations, nor adherence to instructions and recommended dose on pesticide labels. To estimate the marginal productivity of pesticides, we employed two models, namely, the C-D production function model and the damage control model based on Weibull distribution. Our findings suggested that the marginal productivity of pesticides calculated by the C-D production function was 0.39 , while that calculated by the damage control model was 0.40 . As these figures are less than 1 , it means that there is overuse of pesticides in our studied areas. In other words, reducing the amount of pesticide used in agricultural production could be a possible alternative to increase the net income of farmers. Thus, the definition of pesticide overuse in our study is purely financial, and overuse means more than the economic optimum.

Second, our findings do not support the claim that the C-D production function model tends to overestimate the marginal productivity of pesticides. Instead, the estimations in both the C-D production function model and the damage control model are similar.

Third, to explain factors causing overuse, we applied the Binary Probit Regression model for analysis. Our findings suggested that (1) female farmers; (2) farmers with knowledge about pesticide toxicity, pesticide residue and farmers who hold the view that massive use of pesticide is inimical to the environment; and (3) farmers who participate in pesticide training organized by the government, are more likely to overuse pesticide. On the other hand, experienced farmers have a lower chance of overusing pesticides. According to above findings, we propose that the cause of pesticide overuse may be: following the instructions and recommended doses may lead to pesticide overuse; farmers who are loss-averse, in order to avoid the risk of income loss that may be caused by disease and insect pests, and keep its own income stable, will still increase the amount of pesticide application. For the farmers who are loss-averse, the net income increased by reducing the amount of pesticide application is lower 
than the loss of income that may be caused by reducing the amount of pesticide application. It also indicates that farmers are insensitive to increased input of pesticide overuse.

In terms of policy implications, we have the following three policy suggestions: (1) targeted knowledge and skills training without formalization should be provided for farmers in pesticide application; (2) government regulations on pesticide manufacturer be reviewed and monitoring on the recommended amounts of pesticide be reconsidered; (3) price leverage be used to improve farmers' sensitivity to the cost of pesticide input.

Acknowledgments: The research presented in this paper is supported by the National Natural Science Foundation of China (Project Approval No. 71673115, 71540008 and 71633002).

Author Contributions: Jianhua Wang conceptualized and designed the study, and wrote the paper; May Chu jointly designed the study and provided comments on the paper; Yuting Ma collected, analyzed the data and revised the manuscript. All authors read and approved the final manuscript.

Conflicts of Interest: The authors declare no conflict of interest.

\section{References}

1. Liu, C.J.; Men, W.J.; Liu, Y.J.; Zhang, H. The pollution of pesticides in soils and its bio-remediation. Syst. Sci. Compr. Stud. Agric. 2002, 18, 291-292.

2. Mi, J.W.; Huang, J.K.; Chen, R.J.; Liu, E.M. Risk aversion and pesticide application behavior of Cotton farmers in China. Chin. Rural Econ. 2012, 7, 60-71. (In Chinese)

3. Wang, C.W.; Gu, H.Y. The market vs. the government: What forces affect the selection of amount of pesticide used by China's vegetable grower? Manag. World 2013, 29, 50-66.

4. Schultz, T.W. Transforming Traditional Agriculture; Yale University Press: New Haven, CT, USA, 1964.

5. Kahneman, D.; Tversky, A. Prospect theory: An analysis of decision under risk. Econometrica 1979, 47, 263-291. [CrossRef]

6. World Resource Institute (WRI). World Resource 1998/1999; Oxford University Press: Oxford, UK, 1998.

7. Chambers, R.G.; Lichtenberg, E. Simple econometrics of pesticide productivity. Am. J. Agric. Econ. 1994, 76, 407-417. [CrossRef]

8. Ajayi, O.O. Pesticide Use Practices, Productivity and Farmers' Health: The Case of Cotton-Rice Systems in Côte d'Ivoire, West Africa; Pesticide Policy Project; University of Hanover: Hanover, Germany, 2000.

9. Headley, J.C. Estimating the productivity of agricultural pesticides. Am. J. Agric. Econ. 1968, 50, 13-23. [CrossRef]

10. Campbell, H.F. Estimating the marginal productivity of agricultural pesticides: The case of tree-fruit farms in the Okanagan Valley. Can. J. Agric. Econ. 1976, 24, 23-30. [CrossRef]

11. Carlson, G.A. Long-run productivity of insecticides. Am. J. Agric. Econ. 1977, 59, 543-548. [CrossRef]

12. Fernandez-Cornejo, J.; Jans, S.; Smith, M. The economic impact of pesticide use in US agriculture. In Proceedings of the NAREA Meeting, Atlantic City, NJ, USA, 7-9 June 1996.

13. Babcock, B.A.; Lichtenberg, E.; Zilberman, D. Impact of damage control and quality of output: Estimating pest control effectiveness. Am. J. Agric. Econ. 1992, 74, 163-172. [CrossRef]

14. Lichtenberg, E.;Zilberman, D. The econometrics of damage control: Why specification matters. Am. J. Agric. Econ. 1986, 68, 261-273. [CrossRef]

15. Huang, J.; Qiao, F.; Zhang, L.; Rozelle, S. Farm Pesticide, Rice Production, and Human Health; International Development Research Centre: Ottawa, ON, Canada, 2000.

16. Huang, J.; Hu, R.; Rozelle, S.; Qiao, F.; Pray, C.E. Transgenic varieties and productivity of smallholder cotton farmers in China. Aust. J. Agric. Resour. Econ. 2002, 46, 367-387. [CrossRef]

17. Jha, R.K.; Regmi, A.P. Productivity of Pesticides in Vegetable Farming in Nepa; SANDEE Working Paper No. 43-09; SANDEE: Kathmandu, Nepal, 2009.

18. Gong, J.H.; Huang, M.S.; Ma, Y.S.; Sun, J. Cultural background, Eco-environment awareness and pesticide application behavior of farmers. J. Ecol. Rural Environ. 2016, 32, 546-551.

19. Abhilash, P.C.; Singh, N. Pesticide use and application: An Indian scenario. J. Hazard. Mater. 2009, 165, 1-12. [CrossRef] [PubMed]

20. Stadlinger, N.; Mmochi, A.J.; Dobo, S.; Gyllbäck, E.; Kumblad, L. Pesticide use among smallholder rice farmers in Tanzania. Environ. Dev. Sustain. 2011, 13, 641-656. [CrossRef] 
21. Zhao, J.X.; Zhang, Z.G. Analysis of Factors Influencing Farmers' Safe Production of Agricultural Products. Stat. Res. 2007, 24, 90-92.

22. Jia, X.L.; Dong, H.R.; Qi, L.L.; Wang, J.P. Study on using pesticide behavior of the vegetable growers-In Hebei province. Issues For. Econ. 2011, 31, 266-270.

23. Hashemi, S.M.; Hosseini, S.M.; Hashemi, M.K. Farmers' perceptions of safe use of pesticides: Determinants and training needs. Int. Arch. Occup. Environ. Health. 2012, 85, 57-66. [CrossRef] [PubMed]

24. Wu, L.H.; Ho, B.; Gao, S.R. Cognition and main influential factors of pesticide residues in dispersed farmers based on structural equation model. Chin. Rural Econ. 2011, 27, 35-48.

25. Wang, J.H.; Ma, Y.T.; Li, Q. Agricultural products security and the choice of agricultural producers' pesticide application behavior. J. Public Manag. 2015, 12, 117-126, 158.

26. Zhang, Y.H.; Ma, J.J.; Kong, X.Z. Analysis on the factors influencing non-pollution and green pesticide behavior of farmers-An empirical analysis of 15 Counties in Shanxi, Shaanxi and Shandong Provinces. Chin. Rural Econ. 2004, 20, 41-49.

27. Zhou, F.; Xu, X. Analyzing moral hazard behaviors of non-environmental pollution agri-product producers under the government regulation-Based on a survey of rural households in Jiangsu. J. Nanjing Agric. Univ. (Soc. Sci. Ed.) 2007, 7, 25-31.

28. Zhu, D.; Zhang, X.L.; Niu, L.Y. Vegetable farmers' willingness to adopt biopesticides. China Popul. Resour. Environ. 2014, 24, 64-70.

29. Wang, J.H.; Ma, Y.T.; Liu, Z.; Shan, L.J. Behavior choice logic and influencing factors of agricultural producers' pesticide application. China Popul. Resour. Environ. 2015, 25, 153-161. [CrossRef] [PubMed]

30. Wang, Y.Q.; Zhu, Y.C. Influencing factors of farmers' pesticides overuse. Res. Econ. Manag. 2013, 34, 86-91.

31. Tan, H.M. Scientific understanding and effective response to rice quality and safety issues. Grain Sci. Technol. Econ. 2014, 39, 14-17.

32. Zhao, Q.Q. Research on Present Status and Problems of Pesticide Application of Main Crops in China; Beijing Institute of Technology: Beijing, China, 2015.

33. Beattie, B.R.; Taylor, C.R.; Watts, M.J. The Economics of Production; No. 338.5 B369; Wiley: New York, NY, USA, 1985.

34. Norwood, F.B.; Marra, M.C. Pesticide productivity: Of bugs and biases. J. Agric. Resour. Econ. 2003, $28,596-610$.

35. Shankar, B.; Thirtle, C. Pesticide productivity and transgenic cotton technology: The South African smallholder case. J. Agric. Econ. 2005, 56, 97-116. [CrossRef]

36. Praneetvatakul, S.; Kuwattanasiri, D.; Waibel, H. The productivity of pesticide use in rice production of Thailand: A damage control approach. In Proceedings of the International Symposium on Sustaining Food Security and Managing Natural Resources in Southeast Asia: Challenges for the 21st Century, Chiang Mai, Thailand, 8-11 January 2002; p. 14.

37. Schroder, D.; Headley, J.C.; Finley, R.M. The contribution of herbicides and other technologies to corn production in the Corn Belt region, 1964 to 1979. North Cent. J. Agric. Econ. 1984, 6, 95-104. [CrossRef]

38. Stifel, D.; Minten, B. Isolation and agricultural productivity. Agric. Econ. 2008, 39, 1-15. [CrossRef]

39. Talpaz, H.; Borosh, I. Strategy for pesticide use: Frequency and applications. Am. J. Agric. Econ. 1974, 56, 769-775. [CrossRef]

40. Johnston, J.; DiNardo, J. Econometric Methods; McGraw-Hill: New York, NY, USA, 1972; Volume 2.

41. Edwards, W. The theory of decision making. Psychol. Bull. 1954, 51, 380-417. [CrossRef] [PubMed]

42. Doss, C.R.; Morris, M.L. How does gender affect the adoption of agricultural innovations? Agric. Econ. 2001, 25, 27-39. [CrossRef]

43. Li, H.M.; Fu, X.H.; Wu, X.M. Farmers' willingness to use pesticides safely and its influencing factors: A survey and analysis of 214 households in Guanghan City, Sichuan Province. J. Agrotech. Econ. 2007, 26, 99-104.

44. Jallow, M.F.; Awadh, D.G.; Albaho, M.S.; Devi, V.Y.; Thomas, B.M. Pesticide risk behaviors and factors influencing pesticide use among farmers in Kuwait. Sci. Total Environ. 2017, 574, 490-498. [CrossRef] [PubMed]

45. Zhu, D.; Kong, X.; Gu, J.P. Irrational equilibrium of excessive application of pesticides of farmers: Evidence from farmers in Southern China. Chin. Rural Econ. 2014, 30, 17-29.

46. Hruska, A.J.; Corriols, M. The impact of training in integrated pest management among Nicaraguan maize farmers: Increased net returns and reduced health risk. Int. J. Occup. Environ. Health 2002, 8, 191-200. [CrossRef] [PubMed] 
47. Mekonnen, Y.; Agonafir, T. Pesticide sprayers' knowledge, attitude and practice of pesticide use on agricultural farms of Ethiopia. Occup. Med. 2002, 52, 311-315. [CrossRef]

48. Plianbangchang, P.; Jetiyanon, K.; Wittaya-Areekul, S. Pesticide use patterns among small-scale farmers: A case study from Phitsanulok, Thailand. Southeast Asian J. Trop. Med. Public Health 2009, 40, 401-410. [PubMed]

49. Damalas, C.A.; Khan, M. Pesticide use in vegetable crops in Pakistan: Insights through an ordered probit model. Crop Prot. 2017, 99, 59-64. [CrossRef] 